Grand Valley State University

ScholarWorks@GVSU

\title{
Individual and Group Performance on Insight Problems: The Effects of Experimentally Induced Fixation
}

Christine M. Smith

Grand Valley State University, smithc@gvsu.edu

Emily Bushouse

Michigan State University

Jennifer Lord

Grand Valley State University

Follow this and additional works at: https://scholarworks.gvsu.edu/psy_articles

Part of the Psychology Commons

\section{ScholarWorks Citation}

Smith, Christine M.; Bushouse, Emily; and Lord, Jennifer, "Individual and Group Performance on Insight Problems: The Effects of Experimentally Induced Fixation" (2009). Peer Reviewed Articles. 34.

https://scholarworks.gvsu.edu/psy_articles/34

This Article is brought to you for free and open access by the Psychology Department at ScholarWorks@GVSU. It has been accepted for inclusion in Peer Reviewed Articles by an authorized administrator of ScholarWorks@GVSU.

For more information, please contact scholarworks@gvsu.edu. 


\title{
Individual and group performance on insight problems: The effects of experimentally induced fixation
}

Group Processes \& Intergroup Relations 13(1) 91-99

(C) The Author(s) 2009

Reprints and permission: http://www. sagepub.co.uk/journalsPermission.nav DOI: $10.1177 / 1368430209340276$ http://gpi.sagepub.com

(S)AGE

\author{
Christine M. Smith, ${ }^{1}$ Emily Bushouse, ${ }^{2}$ and \\ Jennifer Lord ${ }^{1}$
}

\begin{abstract}
Recent research has shown that the benefits associated with incubation periods during individual problem solving can be explained in terms of forgetting the material or of any strategy that serves to block progress toward success (e.g., Smith \& Blankenship, 1991). While interacting groups reliably outperform individuals on both problem-solving and recall tasks, groups' superior memory capacity may serve to hinder problem solving, especially when fixation has occurred. In the present study, individuals and three-person groups attempted to solve a set of 20 rebus puzzles on two different occasions. In the first session rebuses were accompanied by "clues," that were designed to either help or hinder problem solving. Following a 15-minute filled incubation period, the rebuses were again presented without the clues. As expected, groups recalled more of the clues than did individual problem solvers. Additionally, individual problem-solvers' performance was improved following the incubation period on the misleading clue items but not the good clue items. Following incubation, groups improved on both the helpful and misleading clue items. The possibility that incubation effects may vary with task type in group problem-solving contexts is discussed.
\end{abstract}

\section{Keywords}

fixation in groups, group problem solving, incubation effects

Paper received 4 October 2008; revised version accepted 20 May 2009.

A relatively large and reliable "group superiority effect" can be found in the research tradition comparing individual to group information processing (Hinsz, Tindale, \& Vollrath, 1997; Shaw, 1932; Vollrath, Sheppard, Hinsz, \& Davis, 1989). Of particular relevance to the present paper is the robust finding that collaborative recall is superior to individual recall (Clark \& Stephenson, 1989; Hinsz, 1991; Hoppe, 1962; Lorge \& Solomon, 1962; Tindale \& Sheffey, 2002; Weldon
\& Bellinger, 2000) for a wide variety of stimuli (e.g., nonsense syllables, words, stories, events).

\footnotetext{
${ }^{1}$ Grand Valley State University

${ }^{2}$ Michigan State University

Corresponding author:

Christine M. Smith, Department of Psychology,

Grand Valley State University, Allendale, MI 49401, USA

[email: SmithC@gvsu.edu]
} 
Groups are assumed to outperform individuals on tasks involving recall because of their larger storage capacity, their ability to distribute and organize information in transactive memory systems (Wegner, 1987), and because of the crosscuing that occurs in collaborative recall (Meudell, Hitch, \& Boyle, 1995; Stasson \& Bradshaw, 1995). Cross-cuing occurs when the memories recalled by one group member prompt fellow group members to recall information that they would otherwise have failed to retrieve. The increased capacity to encode, store, and retrieve information possessed by groups is assumed to be associated with enhanced problem solving, which, in part, accounts for the extremely robust finding that groups outperform individuals on problemsolving tasks (Davis, 1969; Hinsz et al., 1997).

While it is intuitively appealing to assume that enhanced memory processes necessarily lead to better problem solving, the act of forgetting may also produce better problem-solving performance under certain conditions, especially in contexts where fixation has occurred (Smith, \& Blankenship, 1989, 1991; Smith \& Vela, 1991). Analogous to a "mental rut," fixation occurs when an individual fails to abandon faulty information or ineffective strategies in her/his attempt to solve a problem, thereby preventing insightful discovery (Duncker, 1945; Luchins, 1942). One well-explored remedy for fixation involves spending time away from the problem, or incubation (Olton, 1979). While explanations for the incubation process are varied, the forgetting-fixation hypothesis is of particular importance in this study (Smith \& Blankenship, 1989).

According to the forgetting-fixation hypothesis, the faulty information or strategy applied during the fixation state blocks the ability to retrieve alternative strategies or more appropriate information from memory. Incubation periods allow for the forgetting of inappropriate information, thereby making appropriate information more accessible in memory (Smith, 1995). Smith and his colleagues, using a wide variety of research paradigms and experimental tasks, have generated ample evidence in support of the forgettingfixation hypothesis (Smith \& Blankenship, 1991;
Smith \& Tindell, 1997; Smith \& Vela, 1991). In one study, individuals were asked to solve several rebus puzzles under conditions of experimentally induced fixation (Smith \& Blankenship, 1989). Rebuses are word/picture puzzles that typically represent common sayings or phrases. For example, "wheather" represents the expression "an ill spell of weather" and "you just me" represents the expression "just between you and me." Smith and Blankenship (1989) created states of fixation by presenting misleading "clues" that were demonstrated to hinder problem solving along with several of the rebus problems (e.g., the words "or not" with the ill spell of weather puzzle or "beside" with the puzzle just between you and me). Consistent with the forgetting-fixation hypothesis, the blocking effect created by the misleading clues diminished over time and higher rates of problem solving were associated with longer incubation periods. That is, with the passage of time the misleading clue that was designed to block the generation of the puzzle's correct solution became less accessible to the problem solver (i.e., it was forgotten), thereby making it more likely that the individual would access more appropriate information.

In the present study we examined the forgetting-fixation hypothesis within the context of freely interacting three-person groups. More specifically, we explored the possibility that a group's superior memory capacity could serve to hinder its problem-solving ability under conditions of experimentally induced fixation. When problemsolving success is dependent upon the forgetting of that which blocks access to relevant information, groups may be at a distinct disadvantage, at least relative to individuals, because the likelihood that groups will abandon an ineffective strategy through the process of forgetting is much lower than it is for individuals. Stated somewhat differently, in contexts where fixation has occurred, the benefits that are typically associated with incubation periods for the individual problem solver may be less pronounced in a group problem-solving context.

We employed a slightly modified version of the Smith and Blankenship (1989) paradigm in 
that a set of rebus puzzles, half associated with helpful clues and half associated with misleading clues were presented to individuals and threeperson groups at two points in time. At the pretest, each rebus puzzle was presented along with a clue. Following the 15-minute incubation period, each rebus puzzle was presented again, this time without its corresponding clue. Consistent with several well-established principles of group information processing as well as the forgetting-fixation hypothesis, it was hypothesized that groups would recall more of the associated clues following an incubation period than would individuals. Consequently, in light of their enhanced ability to recall the associated clues, groups were predicted to perform best on the rebus puzzles paired with helpful clues (i.e., remembering useful information would facilitate solving the puzzle) and less well on the rebus puzzles paired with misleading clues (i.e., remembering misleading information would block access to the problem's solution). A pattern opposite that predicted for group problem solvers was expected for the individuals. That is, individuals were expected to perform best on the items associated with misleading clues (i.e., forgetting the misleading clue would allow more appropriate information to be accessible).

While opposite patterns across the two puzzle types are expected for individuals and groups, it was considered likely that groups would still outperform individual problem solvers. In other words, while groups might not be able to reap the benefits associated with incubation to the same degree that individuals were expected to, this difference was not expected to attenuate or completely cancel out the known benefits associated with problem-solving in groups. This prediction is consistent with the "truthwins" group decision process that has been demonstrated in past research comparing individual to group performance on problems with highly demonstrable solutions (Laughlin \& Ellis, 1986; Laughlin, Kerr, Munch, \& Haggarty, 1976), as well as Lorge and Solomon's (1955) "Model A," an early mathematical model of group performance. Each states that the probability of a group solving a particular problem correctly is equal to the probability that the group contains at least one member who is capable of solving the problem correctly. That is, once a single individual within the group generates the correct response, as long as she/he can demonstrate the veracity of the position to others, she/he has little difficulty convincing the group to adopt that response as their own. When groups work on easily demonstrated intellective tasks (i.e., tasks with correct responses) they outperform the average individual, but not necessarily the "best" individuals (but see Laughlin, Hatch, Silver, \& Boh, 2006).

\section{Method}

\section{Participants and design}

One hundred and twenty-six introductory psychology students at a large Midwestern University were randomly assigned to participate as either individuals $(N=24)$ or as members of three-person groups ( $N=102,34$ groups). All participants received course credit for their involvement in the experiment. A 2 (problem-solving entity: Group/ Individual) $\times 2$ (clue type: Helpful/Misleading) $\times 2$ (time of performance: Pretest/Posttest) mixed design was used. Both clue type and time of performance were within-subjects variables.

\section{Experimental stimuli}

A set of 20 (4 extremely easy, 16 difficult) rebus puzzles were developed for use in the study. A "clue" was developed for each rebus puzzle and 12 clues were designed to increase the likelihood that the rebus puzzle was solved. Eight "clues" were designed to hinder solving the rebuses with which they were associated. Extensive pilot testing of the rebuses and the clues verified their overall level of difficulty as well as the effects of each clue. ${ }^{1}$ The four easy rebus puzzles were associated with extremely helpful clues and these puzzles were presented first in an attempt to enhance the perception that the clues would indeed facilitate solving the puzzles. These easy rebus problems were solved by all participants in the study and were not included in any of the analyses presented below (i.e., the analyzed problem set included 16 difficult rebus problems, 
eight with helpful clues and eight with clues designed to hinder performance).

\section{Procedure}

The entire experiment was presented to participants via the stimulus presentation software SuperLab 4.0. Individuals and three-person groups were seated in front of a large computer screen and given a sheet with 20 numbered lines on which to record their answers (in the group condition the sheet was given to a single randomly chosen individual). The first screen of the program, shown at the start of the experiment, contained detailed instructions regarding how the participants were to move through the experiment. In addition, they were also shown two sample rebus problems along with an explanation regarding how they were to be solved. Participants were not aware that they would be tested on the rebus problems a second time nor that their memory for the clues would be assessed. Participants in the group condition were asked to work collaboratively on the puzzles.

Before each puzzle, a clue was presented for three seconds followed immediately by the rebus which was shown for 30 seconds. ${ }^{2}$ The participants were not allowed to return to a rebus puzzle once it had disappeared from the screen. After the last rebus problem was presented, all participants were given a filler task which consisted of ten difficult mathematical "brain-teaser" puzzles, each presented for 90 seconds. These problems created the 15-minute filled incubation period. Following the incubation period, all participants were once again shown the 20 rebus problems for 30 seconds each, but on this trial the puzzles were presented without their respective "clues." Additionally, the order in which the rebuses were presented differed from the pretest. Finally, participants were shown the 20 rebuses (in yet another random order) and were asked to recall and record the clue that was associated with each rebus puzzle.

\section{Results}

Clue memory was analyzed with a 2 (problemsolving entity: Group/Individual) $\times 2$ (clue type: Helpful/Misleading) ANOVA. As expected, groups recalled more clues $(M=6.69, S D=.13)$ than did individuals $(M=3.98, S D=.19), F(1,56)=$ 121.36, $p=.01, \eta^{2}=.64$. Helpful clues were recalled more frequently $(M=5.92, S D=.155)$ than misleading clues $(M=4.74, S D=.150), F(1,56)=$ $43.04, p=.01, \eta^{2}=.43$. However, clue type did not interact with problem-solving entity, $F(1,56)=$ $.611, p=.44$. That is, group recall $(M=7.35$, $S D=1.09)$ exceeded individual recall $(M=4.50$, $S D=.23)$ for helpful clues as well as misleading clues $(M=6.03, S D=.93$ and 3.46, $S D=.23$, respectively).

Solutions to the 16 difficult/critical rebus problems were analyzed with a 2 (problemsolving entity: Group/individual) $\times 2$ (clue type: Helpful/misleading) $\times 2$ (time of performance: Pretest/Posttest) mixed ANOVA. The means and standard deviations for each condition are presented in the top half of Table 1. With respect to main effects, as predicted, groups outperformed individual problem solvers, $F(1,56)=36.78, p=.01, \eta^{2}=.40$. Performance improved from pretest to posttest, $F(1,56)=$ 95.43, $p=.01, \eta^{2}=.63$, and rebuses that were associated with helpful clues were solved at a higher rate than were those that were associated with misleading clues, $F(1,56)=4.58, p=.04$, $\eta^{2}=.08$. Time of performance interacted with problem-solving entity, $F(1,56)=7.74, p=$ $.01, \eta^{2}=.12$. That is, group performance improved more than did individual performance from pretest to posttest. Clue type interacted with problem-solving entity $F(1,56)=$ 9.18, $p=.01, \eta^{2}=.14$. Overall, groups performed worse on the rebuses associated with misleading clues relative to helpful clues, whereas individuals performed similarly on helpful and misleading clue rebuses. The three-way (Entity $\times$ Clue Type $\times$ Time) interaction was not significant, $F(1,56)=.37, p=.54$. 
Table 1. Mean number of rebus puzzles solved prior to (pre) and following (post) 15-minute incubation period

\begin{tabular}{|c|c|c|c|c|}
\hline & \multicolumn{4}{|c|}{ Rebus type } \\
\hline & \multicolumn{2}{|c|}{ Helpful clue } & \multicolumn{2}{|c|}{ Misleading clue } \\
\hline & Pre & Post & Pre & Post \\
\hline \multicolumn{5}{|c|}{ Problem solving entity } \\
\hline Individuals & $1.50(1.25)$ & $1.71(1.30)$ & $1.21(1.02)$ & $2.37(1.34)$ \\
\hline Groups & $3.62(1.75)$ & $4.24(1.60)$ & $1.91(1.02)$ & $3.76(1.67)$ \\
\hline \multicolumn{5}{|l|}{ Nominal groups* } \\
\hline Best member & $.75(.70)$ & $1.12(.83)$ & $1.00(.75)$ & $1.75(1.28)$ \\
\hline Worst member & $2.37(1.68)$ & $2.25(1.58)$ & $1.25(1.38)$ & $2.62(1.50)$ \\
\hline
\end{tabular}

Note: *Best and worst member determined by number of clues recalled. Standard deviations in parentheses.

The overall performance of the individuals was consistent with the fixation-forgetting hypothesis. Performance was significantly improved on the misleading clue items following incubation, $t(23)=$ $4.74, p=.00$ and unchanged on the helpful clue items, $t(23)=1.15, p=.26$. Additionally, at the posttest, individuals performed better on the items associated with misleading clues relative to the items associated with helpful clues, $t(23)=$ $2.71, p=.01$. With respect to group performance, significant improvements following incubation were found for both misleading clue items, $t(33)=$ $7.87, p=.00$ and for helpful clue items, $t(33)=$ $3.91, p=.00$. While the difference between helpful and misleading clue items at the posttest was in the direction predicted, this difference did not reach statistical significance, $t(33)=1.25, p=.21$.

In order to explore further the groups' enhanced performance on the rebus problems we carried out a set of analyses parallel to those described above but this time compared interacting groups to nominal groups created from the individuals in our sample. Individuals were randomly assigned to one of eight three-person nominal groups. Within each of these groups, the best and worst nominal group member with respect to memory for the rebus clues was identified and her/his solutions to the rebus puzzles were considered as the "best" and "worst" member performances, respectively. Creating such nominal groups allowed us to test group performance relative to the most and least competent members as well as to assess better the extent to which group interaction was beneficial to recall and problem solving (Steiner \& Rajaratnam, 1961). That is, while the above analyses suggest that group performance was superior in all regards, it is important to assess whether interacting groups outperformed the best member on rebus problems associated with good clues as well as whether they outperformed the worst member on problems associated with misleading clues (where forgetting is associated with better performance). While the results of these analyses are interesting, we have interpreted them with some caution given the very small number of nominal groups we were able to create and the resulting insensitivity of the statistical tests we applied (Keppel, 1973).

Clue memory was analyzed with 3 (problemsolving entity: Best nominal group member/Worst nominal group member/Interacting group) $\times$ 2 (Clue type: Helpful/Misleading) ANOVA. As expected, interacting groups recalled more clues $(M=6.69, S D=.13)$ than $\operatorname{did}$ best $(M=4.87, S D=$ $.28)$ and worst $(M=2.94, S D=.28)$ nominal group members, $F(1,47)=80.27, p=.01, \eta^{2}=.77$. All problem-solving entities were significantly different from one another $(p=.01)$. Helpful clues were recalled more frequently $(M=6.44, S D=$ 1.80) than misleading clues $(M=5.16, S D=1.71)$, 
$F(1,47)=25.06, p=.01, \eta^{2}=.35$. However, clue type did not interact with problem-solving entity, $F(1,47)=.06, p=.93$. That is, interacting groups' recall $(M=7.35, S D=1.9)$ exceeded best nominal group members' recall $(M=5.50, S D=.92)$ and worst nominal group members' recall $(M=3.50$, $S D=1.19)$ for helpful clues as well as for misleading clues $(M=6.03, S D=.93 ; M=4.24, S D=1.03$; $M=2.38, S D=1.30$, respectively).

Solutions to the 16 difficult/critical rebus problems were analyzed with a 3 (problem-solving entity: Best nominal group member/Worst nominal group member/Interacting group) $\times 2$ (clue type: Helpful/misleading) $\times 2$ (time of performance: Pretest/Posttest) mixed ANOVA. The means and standard deviations for each nominal group type are presented in the bottom half of Table 1. With respect to main effects, performance varied as a function of problem-solving entity $F(2,47)=$ $16.37, p=.01, \eta^{2}=.41$. Interacting groups performed significantly better than the best nominal group members $(p=.01)$ and better than the worst nominal group members $(p=.01)$. The nominal group members with the worst clue memory outperformed the nominal group members with the best clues memory; however, this difference was only marginally significant $(\phi=.07)$. Performance improved from pretest to posttest, $F(1,47)=38.40$, $p=.01, \eta^{2}=.45$. Rebuses that were associated with helpful clues were not solved at a higher rate than were those that were associated with misleading clues, $F(1,47)=1.34, p=.25$. Time of performance interacted with problem-solving entity, $F(2,47)=4.10, p=.02, \eta^{2}=.14$. That is, change from pretest to posttest was significantly greater for interacting groups than it was for either best or worst nominal group members. There was a marginally significant interaction between clue type and problem-solving entity $F(2,47)=2.91, p=.06$, $\eta^{2}=.11$. Performance on the good clue items is significantly better than performance on the misleading clue items for interacting groups $(p=.01)$. Clue type is not reliably associated with performance for best member or for worst member nominal groups ( $p=.11$ and .24 , respectively). The threeway $($ Entity $\times$ Clue Type $\times$ Time $)$ interaction was not significant, $F(2,47)=.99, p=.37$.
Interacting groups outperformed the best members of nominal groups on the items associated with helpful clues, $F(1,40)=26.06, p=.01$, $\eta^{2}=.39$. Likewise, interacting groups outperformed the worst members of nominal groups on items associated with misleading clues; however this difference was only marginally significant, $F(1,40)=.06, \eta^{2}=.08$.

\section{Discussion}

Successful problem solving is often dependent upon the ability to abandon faulty information or ineffective strategies in favor of more effective alternatives. The ease with which one successfully adopts new alternatives is determined, in part, by the extent to which old alternatives interfere with or block the generation of more suitable problem-solving strategies. In the present study we explored the possibility that when faced with fixation, groups would benefit less from incubation periods, relative to individuals, because they would be less inclined to forget that which serves to block alternative strategy generation. As expected, groups did recall more of the clues associated with the rebus problems than did the individuals. Additionally, consistent with the work on collaborative recall, interacting groups performed better than the best member of nominal groups with respect to clue recall. Also consistent with predictions, groups solved more of the rebus puzzles than did individuals. This general pattern was also observed when individuals were combined to create nominal groups. Clearly, group interaction was associated with enhanced performance with respect to both recall and problem solving.

While individuals exhibited the problemsolving patterns predicted by the fixation-forgetting hypothesis, group performance improved following incubation on both the helpful and the misleading clue items, this, despite the fact that their memory for the misleading clues was quite high. Stated somewhat differently, groups appear to have benefited from incubation in a manner quite inconsistent with the fixation-forgetting hypothesis. Contrary to the prediction explicated, the increment of improvement following incubation for groups 
was greatest for rebus puzzles associated with misleading clues. Several possible explanations exist for the overall group problem-solving patterns found.

It is possible that the misleading clues failed to create a state of fixation within the groups comparable to that experienced by the individuals. While this possibility cannot be completely ruled out with the data we have available to us, it seems a less likely explanation in light of the groups' performance on the pretest rebus puzzles associated with misleading clues. Clearly, the misleading clues appear to have interfered with the groups' ability to generate correct solutions to the puzzles at the pretest.

An alternative and perhaps more interesting explanation involves the possibility that fixated states were not experienced uniformly by group members, that is, all group members did not remember the associated clues following the incubation period (a likely outcome if one generalizes from the individual clue memory data). If groups did not begin their second attempt to solve the rebus problem by first generating the clue from an individual's memory, some individual members of the group may have indeed benefited from the incubation period (i.e., forgotten the clue that served to block the solution). This possibility is especially important to explore in light of the nature of the task used in this particular study. While the rebus problems were quite difficult, they were likely extremely high in demonstrability (i.e., a eureka-type task). That is, once a group member discovered the solution to the puzzle, it was unlikely that she/he experienced difficulty convincing fellow group members to adopt that answer. Therefore, it may be that those who had forgotten the clue were also the ones to generate the solution to the rebus puzzle. In this particular context, then, the process that occurred may have been analogous to the "truthwins" decision process that is reliably observed in the group problem-solving literature (e.g., Laughlin \& Ellis, 1986). That is, groups escaped their fixated state when at least one individual who was capable of solving the problem also forgot the information that blocked access to the solution.
When working on a eureka task, the presence of one solver is predictive of the group solving the problem. Likewise it may be that when fixated, a group's success is determined, at least in part, by the presence of a member who is no longer in a fixated state. The performance of the nominal group members with the worst memories for the clues is consistent with this notion; however, it is important to note that interacting groups outperformed these nominal groups. While all of the analyses carried out are consistent with the notion that the group interaction process was critical to the enhanced group performance observed in this study, the nature of this process cannot be understood fully given the nature of the data presently available to us. The collection of group interaction process data seems essential to developing such an understanding.

Additionally, it seems important that future research systematically address both group problem-solving norms and task characteristics as important variables in predicting the effects of incubation in problem-solving groups. If, for example, groups develop a norm whereby they reliably return to where they left off right before an incubation period and it is customary to state this explicitly (in this context, first generating the clue, stating the clue out loud and then proceeding to search for the solution), we would predict that the benefits associated with incubation would be attenuated for groups relative to individuals. That is, returning to where one left off would serve to ensure uniform fixation states across group members. Likewise, it is our suspicion that the effects associated with incubation in groups is also likely to vary along the task demonstrability dimension. Solutions to tasks low in demonstrability may seem less "correct" if the solution deviates considerably from the information/ strategy that serves to create a fixated state. For example, creative solutions to problems and innovative ideas may be less well received by fellow group members who are intent upon adhering to an old plan.

While we are unable to offer an unequivocal explanation for the group problem-solving patterns found, the current study serves as a valuable 
first step towards understanding incubation effects in groups while also generating many interesting questions that ought to be addressed in future research.

\section{Notes}

1. Pilot testing was carried out with individual problem solvers and involved comparing solution rates under clue present and clue absent conditions. All of the helpful clue puzzles in the current research were solved significantly more frequently under clue present conditions and significantly less frequently under clue present conditions when the associated clue was misleading.

2. The exposure duration for each rebus problem was exactly that used by Smith \& Blankenship (1989).

\section{References}

Clark, N. K., \& Stephenson, G. M. (1989). Group remembering. In P. Paulus (Ed.), The psychology of group influence (2nd ed., pp. 357-392). Hillsdale, NJ: Erlbaum.

Davis, J. H. (1969). Group Performance. Reading, MA: Addison-Wesley.

Duncker, K. (1945). On problem solving. Psychological Monographs, 58 (Whole No. 270).

Hinsz, V. B. (1991). Cognitive and consensus processes in group recognition memory performance. Journal of Personality and Social Psychology, 59, 705-718.

Hinsz, V. B., Tindale, R. S., \& Vollrath, D. A. (1997). The emerging conception of groups as information processors. Psychological Bulletin, 121, 43-64.

Hoppe, R. A. (1962). Memorizing by individuals and groups: A test of the pooling-of-ability model. Journal of Abnormal and Social Psychology, 65, 64-67.

Keppel, G. (1973). Design and analysis: A researcher's handbook. Englewood Cliffs, NJ: Prentice-Hall.

Laughlin, P. R., \& Ellis, A. L. (1986). Demonstrability and social combination processes on mathematical intellective tasks. Journal of Experimental Social Psychology, 22, 177-189.

Laughlin, P. R., Hatch, E., Silver, J., \& Boh, L. (2006). Groups perform better than the best individuals on letters-to-numbers problems: Effects of group size. Journal of Personality and Social Psychology, 90, 644-651. Laughlin, P. R., Kerr, N. L., Munch, M. M., \& Haggarty, C. A. (1976). Social decision schemes of the same four-person groups on two different intellective tasks. Journal of Personality and Social Psychology, 33, 80-88.

Lorge, I., \& Solomon, H. (1955). Two models of group behavior in the solution of Eureka-type problems. Psychometrika, 20, 139-148.

Lorge, I., \& Solomon, H. (1962). Group and individual behavior in free-recall verbal learning. In J. H. Criswell, H. Solomon, \& P. Suppes (Eds.), Mathematical methods in small group processes (pp. 221-231). Stanford, CA: Stanford University Press.

Luchins, A. (1942). Mechanization in problem solving: The effects of Einstellung. Psychological Monographs, 54 (6, Whole No. 248).

Meudell, P. R., Hitch, G. J., \& Boyle, M. M. (1995). Collaboration in recall: Do pairs of people cross-cue each other to produce new memories? Quarterly Journal of Experimental Psychology: Human Experimental Psychology, 48 (A), 141-152.

Olton, R. M. (1979). Experimental studies of incubation: Searching for the elusive. Journal of Creative Behavior, 13, 9-22.

Shaw, M. E. (1932). Comparison of individuals and small groups in the rational solution of complex problems. American Journal of Psychology, 44, 491-504.

Smith, S. M. (1995). Fixation, incubation, and insight in memory, problem solving, and creativity. In S. M. Smith, T. B. Ward, \& R. A. Finke (Eds.), The creative cognition approach (pp. 135-155). Cambridge, MA: MIT Press.

Smith, S. M., \& Blankenship, S. E. (1989). Incubation effects. Bulletin of the Psychonomic Society, 27, 311-314.

Smith, S. M., \& Blankenship, S. E. (1991). Incubation and the persistence of fixation in problem solving. American Journal of Psychology, 104, 61-87.

Smith, S. M., \& Tindell, D. R. (1997). Memory blocks in word fragment completion caused by involuntary retrieval of orthographically similar primes. Journal of Experimental Psychology: Learning, Memory and Cognition, 23, 355-370.

Smith, S. M., \& Vela, E. (1991). Incubated reminiscence effects. Memory and Cognition, 19, 168-176.

Stasson, M. F., \& Bradshaw, S. D. (1995). Explanations of individual-group performance differences: What sort of "bonus" can be gained through group interaction? Small Group Research, 26, 296-308.

Steiner, I. D., \& Rajaratnam, N. (1961). A model for the comparison of individual and group performance scores. Behavioral Science, 6, 142-147. 
SuperLab (Version 4.0) [Software]. Available from http://www.superlab.com

Tindale, R. S., \& Sheffey, S. (2002). Shared information, cognitive load, and group memory. Group Processes \& Intergroup Relations, 5, 5-18.

Vollrath, D. A., Sheppard, B. H., Hinsz, V. B., \& Davis, J. H. (1989). Memory performance by decision making groups and individuals. Organizational Behavior and Human Decision Processes, 43, 289-300.

Wegner, D. M. (1987). Transactive memory: A contemporary analysis of the group mind. In B. Mullen \& G. Goethals (Eds.), Theories of group behavior (pp. 185-208). New York: Springer.

Weldon, M. S., \& Bellinger, K. D. (2000). Collective memory: The nature of individual and collaborative recall. Journal of Experimental Psychology: Learning, Memory, and Cognition, 23, 1160-1175.

\section{Biographical notes}

CHRISTINE M. SMITH is a professor of psychology at Grand Valley State University. Her research focuses on social influence processes within groups, minority influence, and group creativity.

EMILY BUSHOUSE is a graduate student in the Education Specialist program in School Psychology at Michigan State University. Prior to attending MSU, she earned a BSc in psychology from Grand Valley State University.

JENNIFER LORD is a graduate student in social psychology at the University of Kent. Prior to attending Kent, she earned a BSc in psychology from Grand Valley State University. 